\title{
A análise de Heurísticas na Resolução de problemas matemáticos
}

\author{
Analysis of Heuristics in solving Math problems
}

\author{
Rosana Cristina Macelloni Alvarenga ${ }^{1}$ \\ rosanamacelloni@bol.com.br
}

\begin{abstract}
Resumo
Esse trabalho refere-se a uma pesquisa de mestrado que teve como objetivos a análise das heurísticas envolvidas numa experiência de ensino por meio da perspectiva metodológica da resolução de problemas e a análise da relação dos alunos do Ensino Médio com a disciplina Matemática. À luz da Teoria Histórico-Cultural, esse trabalho pode contribuir para análise da subjetividade dos processos de formação de conceitos, dos modos de pensar dos educandos face à aprendizagem Matemática, de sua criatividade e raciocínio lógico ao resolver problemas. A metodologia utilizada foi a pesquisa qualitativa. Os alunos, sujeitos da pesquisa, foram considerados ora como resolvedores, ora como propositores de problemas; os dados foram coletados, em aulas de Matemática, de Maio a Novembro de 2007. Concluímos que a eficiência na sua resolução depende não somente da memória, das ideias prévias e estratégias, mas de todos esses processos enunciados que participam efetivamente da formação do conceito matemático.
\end{abstract}

Palavras-chave: Matemática; Heurísticas; Criatividade; Raciocínio Lógico; Resolução de Problemas; Formação de Conceitos.

\begin{abstract}
This work treats the results of a Master's degree study and it has the objectives to analyze the heuristics involved in a learning experience through the methodological perspective of problem solving and analysis of relationship of high school students with the subject Mathematics. In the light the view of the Historical-Cultural Theory, this paper can contribute for the analysis of the subjectivity of the concept-formation processes, the learners' ways of thinking when talking about the Math's learning, their creativity and logical thinking while solving problems. The methodology applied was the qualitative research. The students, individuals of the research, were considered sometimes problem-solvers and other times problem-proposers; the data were collected, from May to November, 2007. The results appointed that the efficiency in this resolution depends not only memory, previous ideas and strategies, but through all these mentioned processes that effectively take part in the formation of the Math concept.
\end{abstract}

Keywords: Mathematics; Heuristics; Creativity; Logical Thinking; Problems-Solving; Concept-Formation

\footnotetext{
${ }^{1}$ Doutoranda em Educação para a Ciência (UNESP). Universidade Estadual Paulista "Júlio de Mesquita Filho" (Bauru-SP), Professora Efetiva da Rede Estadual de Ensino do Estado de São Paulo e Professora do Instituto Superior de Educação de Garça - SP.
} 


\section{Introdução}

O presente artigo retrata de forma resumida a dissertação de mestrado defendida em 2008 pela autora do mesmo. A pesquisa desenvolvida buscou a análise das heurísticas dos alunos, na resolução de problemas Matemáticos, análise esta, feita à luz da Teoria Histórico-Cultural ou Histórico-Crítica, ou ainda Escola de Vygotsky. A escolha por essa temática não foi aleatória, a Matemática sempre exerceu um fascínio sobre a autora, sentindo a necessidade, consequentemente, de levá-la à apropriação dos outros também. A possibilidade de analisar como os alunos pensam certas situações-problema sempre a encantou; poder investigar as diferenças de pensamentos ou as heurísticas de cada ser humano nos leva a conhecer melhor o relacionamento de cada um com a Matemática e nos faz ajudá-los no seu desenvolvimento.

Este trabalho foi baseado tanto nas experiências pessoais vividas como aluna de professores que ensinavam por meio da resolução de problemas, em estudos inerentes ao assunto, nas observações realizadas nas classes, bem como na experiência de doze anos como professora, ensinando sob a perspectiva metodológica da resolução de problemas e procurando seguir os ensinos de Vygotsky para uma compreensão dos processos didáticos necessários ao ensino de Matemática voltado para a formação de conceitos dos alunos.

Desde 1994, época do Ensino Médio, cursado em uma escola pública, na modalidade de Curso Técnico de Processamento de Dados, a autora já tinha descoberto a paixão da sua vida, a Matemática, inclusive já dava aulas particulares para os amigos da própria turma e vivenciava o pavor dos colegas a essa disciplina. Posso afirmar que a Matemática a chamou atenção muito precocemente.

Em 1995, foi aprovada no vestibular da UNESP - Campus de Bauru, para o curso de Licenciatura em Matemática. Neste mesmo ano começou a lecionar. Foi, então, que sentiu os percalços da profissão, com apenas 17 anos. Vivenciando uma classe de sexta série do Ensino Fundamental, numa escola pública, (a mesma que mais tarde, em 2004, seria efetiva), e ao deparar com a realidade, decepcionou-se. Ela era muito mais dura e cruel do que pensava, tinha que lidar com todos os tipos de dificuldades tais como: alunos desmotivados, precárias condições de trabalho e salário insuficiente.

Em 1996 não lecionou na escola pública. Pretendia amadurecer suas ideias e metodologias em relação à sua realização como professora desta Ciência desafiadora. Esperava isso na teoria, entretanto, tempos depois, a prática aliada às leituras, trouxe maiores aprendizagens. 
Durante os anos seguintes, de 1997 a 2003, trabalhou como professora admitida em caráter temporário. Sempre pulsava o desejo de aprender mais, aprimorar-se, a fim de proporcionar aos alunos aulas mais interessantes e agradáveis, levando-os a conhecer a verdadeira Matemática, ou seja, aquela Matemática pela qual havia se apaixonado, cheia de desafios, tão bela, útil, curiosa e intrigante. Esse aperfeiçoamento, foi adquirindo com as pessoas com as quais trabalhava, com os alunos, em cada aula ministrada, em cada experiência de ensino vivenciada e com diferentes livros pesquisados.

Também teve a oportunidade de lecionar na EJA, no Projeto de Reforço, no Programa Escola nas Férias, no Supletivo, na Tele-Sala, além das classes regulares em diversas escolas e sem esquecer as aulas particulares em casa. Foram experiências profissionais importantes para o conhecimento das dificuldades, desafios e sucessos do processo de ensino e de aprendizagem.

$\mathrm{Na}$ Faculdade, teve o privilégio de ter aulas com professores que ensinavam por meio de resolução de problemas. Identificando-se com esta metodologia de trabalho e resolvendo que suas práticas pedagógicas também seriam desta forma.

Foi, então, que se inscreveu no Processo de Seleção para o Mestrado no final de 2005 e sendo aprovada, começou a se preparar para esta ação cultural dialógica a serviço da libertação dos homens, entendendo que a resolução de problemas é a matriz geradora de um verdadeiro processo de formação de conceitos.

Sentia-se e sente-se ainda preocupada com o ensino de Matemática em toda sua plenitude, se contrapondo aos métodos dogmáticos, meramente tecnicistas. Pelo amor à Matemática, resolveu mergulhar cada vez mais fundo nos problemas do ensino e da aprendizagem dessa disciplina. Por ela e pelo ensino dela, debruça a estudar novas formas de ensinar, em uma busca constante de aprimorar-se, pois ainda percebe que há muitos mitos e problemas presentes na relação professor-Matemática - aluno.

No ano de 2006, organizou um curso gratuito de Matemática aos sábados no projeto "Escola da Família", na própria instituição em que trabalhava, para fazer observações e aplicar o piloto do projeto. Foi neste "piloto" que aprendeu a fazer os registros descritivos e reflexivos, as anotações organizadas, a concentrar-se durante as observações. Foi uma situação pedagógica de muito valor.

Em 2007, realizou observações em duas salas de aulas de segunda série do Ensino Médio, nas quais era professora, quando houve a coleta definitiva de dados, acumulando, assim, o duplo papel de professora e pesquisadora, a qual resultou essa dissertação, que continua sendo 
aprofundada agora (2013) nos estudos do doutorado, na questão da dialética entre criatividade e Matemática.

\section{O que entendemos por resolução de problemas}

A resolução de um problema, para Polya (1978), envolve, primeiramente, a compreensão do mesmo, depois a elaboração de um plano para solucioná-lo, posteriormente, à execução deste plano (neste momento há a mobilização de conhecimentos e estratégias) sendo que só então o aluno chegará à solução proposta. Por último, ao retrospecto, à verificação de sua resposta e reflexão acerca dos procedimentos adotados para concluí-lo. Lembramos que o processo todo da resolução de problemas, com êxito, depende das atitudes do professor frente a uma aula desta natureza.

A meta é que os educandos aprendam Matemática por sua

especificidade na construção do conhecimento na formação dos indivíduos, levando em consideração aspectos como o de continuidade em relação ao cotidiano e o de ruptura em relação ao senso comum. (MACHADO, 1999, p.19).

Qualquer conteúdo matemático pode ser introduzido com uma situação-problema e depois ser sistematizado formalmente com as regras convencionalmente estabelecidas.

Como ensinar por meio da resolução de problemas? Polya (1978) nos responde esta questão dizendo que se ensina com perguntas, como por exemplo: O que o problema pede? Qual é a incógnita? Como vou resolvê-lo? Você conhece ou já resolveu algum problema parecido?

Notamos certa proximidade entre a proposta de ensino pela resolução de problemas de Polya e o conceito de Zona de Desenvolvimento Proximal de Vygotsky,

quando o professor desafia o aluno com algum problema, ele tem dois objetivos em mente, o primeiro é auxiliá-lo na resolução do mesmo, o segundo objetivo é desenvolver no estudante a capacidade de resolver futuros problemas por si próprios. (POLYA, 1978, p.2).

A aprendizagem do sujeito impulsiona o desenvolvimento de seu ser completo, inteligência e personalidade; o ensino considerado envolvente e colaborativo é o verdadeiro ensino, que incide na zona de desenvolvimento próximo,

por isso é que Vygotsky conclui que o bom ensino não é aquele que incide sobre o que a criança já sabe ou é capaz de fazer, mas é aquele que faz avançar o que a criança já sabe, ou seja, que a desafia para o que ela ainda não sabe ou ainda não é capaz de fazer sem a ajuda de outros. (MELLO, 1999, p.19). 
Conforme Mello (1999), a intervenção do adulto deve ser intencional e sempre na zona de desenvolvimento próximo.

Para Pires (1999), a resolução de problemas é um processo que impregna todo o trabalho e proporciona o aprendizado de conceitos e habilidades. Ela oferece ao educando a possibilidade de ganhar confiança no uso da Matemática e de desenvolver uma atitude de perseverança.

Smole e Diniz (2001) situam historicamente as concepções de resolução de problemas. A primeira é que, primeiro se ensina Matemática para depois resolver problemas; a segunda é que, ao ensinar a resolver problemas, como consequência resultaria em aprender Matemática; a terceira é que, ao considerarmos os problemas que envolvem o conteúdo específico, os diversos tipos de problemas e os métodos de resolução alcançariam à aprendizagem Matemática.

Continuando essa linha de raciocínio, Smole e Diniz (2001) relatam que mais recentemente, nos anos 90, a resolução de problemas ganha outra dimensão, sendo descrita como uma metodologia.

A junção de todos estes conceitos fez surgir uma nova ideia a respeito de resolução de problemas pela autora e um grupo de professores e pesquisadores, com a qual concordo, que é a sua definição como uma perspectiva metodológica, ou seja, qualquer ato no processo de ensino e de aprendizagem que propicia a investigação por parte do aluno está embutido na perspectiva metodológica de resolução de problemas, a resolução de problemas trata de situações que não possuem solução evidente e que
exigem que o resolvedor combine seus conhecimentos e decida pela maneira de usá-
los em busca de solução. (SMOLE; DINIZ, 2001, p.89).

Dante (2005) observa que a resolução de problemas deve ter por meta fazer o aluno pensar; desenvolver o raciocínio lógico; ensiná-lo a enfrentar situações novas; levá-lo a conhecer as primeiras aplicações da Matemática; tornar as aulas mais interessantes e motivadoras.

A perspectiva metodológica da resolução de problemas é concebida como uma atividade construtora de uma aprendizagem significativa e de acordo com Smole e Diniz (2001) esta nova visão rompe a conceituação desta como simples metodologia ou conjunto de orientações didáticas.

Se as situações relevantes ao cotidiano não forem oferecidas ao aluno pela Matemática, surgem, inevitavelmente, perguntas como: “Onde é que vou usar isto?" "Para que serve?". 
Cabe ao professor mostrar que a atividade do homem atual, numa sociedade mutável, já exige, tanto do ponto de vista individual como do social, um conhecimento, o mais completo possível, do mundo que o rodeia e que a Matemática proporciona parte importante desse desenvolvimento, tanto das habilidades e competências básicas para a comunicação e a tomada de decisões, quanto à formação do cidadão crítico, criativo e solidário, capaz de ser agente de mudanças na sociedade em que vive.

Nesse contexto, o educando deve, constantemente, ser encorajado a resolver situaçõesproblema, sejam elas provenientes de ambientes matematicamente criados com materiais manipuláveis, como jogos e pela tecnologia ou advindas do mundo real impregnado de suas vivências e de interesses, ou mesmo do livro didático, desde que permitam o processo investigativo.

A situação-problema é o ponto de partida da ação pedagógica capaz de conduzir à formação de conceito, por fazer parte do cotidiano e favorecer o desenvolvimento da autonomia moral.

\section{O oral e o escrito no ensino de Matemática}

Em geral, a escola age como se a Matemática e a língua materna não fossem impregnadas mutuamente. Para Machado (1999), decisivamente, a Matemática comunga com a língua materna. Por isso, logicamente não seria razoável uma iniciação de qualquer conteúdo matemático através de uma linguagem formal Matemática; a mediação da língua materna funciona como uma ponte que viabiliza contatos com os mais variados discursos.

É possível o trabalho com os gêneros orais na escola e mesmo sendo flexíveis, eles têm certa estabilidade, uma composição, tipo de estruturação e acabamento e tipo de relação com os outros participantes da troca verbal.

Segundo Dolz e Schneuwly (1998), o oral é paradoxalmente ensinado na pré-escola e início do ensino fundamental e no ensino superior. Mas, ele não tem sido objeto de ensino e aprendizagem ao longo do ensino fundamental e médio.

O papel da escola, para Dolz e Schneuwly (1998), é levar os alunos a ultrapassar as formas de produção oral cotidianas para confrontá-las com outras formas mais institucionais, mediadas, parcialmente reguladas por restrições exteriores.

Se há a pretensão da escola em exercer uma ação transformadora, ela deve eleger o diálogo como estratégia para fazer com que o aluno consiga participar do universo de comunicação humana. 
Entendemos que os diálogos matemáticos devem permear as aulas na perspectiva metodológica de resolução de problemas e que é fundamental que o professor promova perguntas como: Qual é a incógnita? O que o problema está pedindo? Quais são os dados?, dentre outras. São perguntas que servem para a compreensão do problema.

Perguntas, como: "Você conhece um problema parecido com este?" ajudam na elaboração de um plano de resolução e perguntas como: "Verificou a resposta em relação ao enunciado"? "Faz sentido esta resposta?" ajudam no retrospecto.

Smole e Diniz (2001) também debatem este assunto da oralidade em Matemática, ressaltam que a comunicação oral favorece a percepção das diferenças, tanto de pessoas, comportamentos, resoluções diferentes de problemas, bem como a convivência dos alunos entre si, o exercício de escutar e a confiança em si mesmos.

O hábito de exporem seus pensamentos desenvolve a fala que ilumina o pensamento, Bakthin (1990) explicita que a linguagem e sua construção, estão ligadas ao pensamento dialético, nas relações contraditórias, as quais buscam a compreensão de uma formação de significados e criação individual e subjetivo de sentidos; ou seja, a questão da formação dos conceitos matemáticos na óptica de alguns aspectos da Teoria Histórico-Cultural, assunto tratado também na dissertação.

Procedimentos, dificuldades e avanços dos alunos na resolução de problemas: as heurísticas

Priorizamos na análise oito situações-problema, são problemas convencionais e nãoconvencionais. Os problemas convencionais são aqueles que não se aproximam do contexto de vida do aluno, a linguagem é distante da comumente usada por ele e eles podem ser resolvidos pela aplicação direta de um ou mais algoritmos. Os problemas não convencionais são aqueles abertos, com mais de uma resposta, ou sem dados, ou mesmo com falta de dados, podem ser impossíveis ou sem solução, com excesso de dados, de lógica, podem ser a partir de gravuras, gráficos, tabelas, artigos de jornais, revistas ou por jogos.

Eles são apresentados em textos mais elaborados, contendo personagens, provocam a imaginação do aluno e sugerem situações inusitadas. Convidam ao raciocínio, motivam e causam encantamento, podem ser resolvidos por diferentes estratégias.

Não houve aqui o propósito de saber quantos alunos acertaram ou erraram as questões apresentadas, por isso, a análise sem julgamento de acertos ou erros, mas houve a análise das diferentes maneiras de pensar das pessoas para resolução de problemas, na verdade, as 
justificativas apresentadas, e como elas foram elaboradas, valorizando-se a criatividade e a diversidade.

Segundo Bruner (1968) em Matemática, esse assunto possui um nome formal, "heurística", para descrever a abordagem feita por alguém ao resolver um problema.

Polya (1978, p.86), dá um significado para heurística:

\begin{abstract}
Heurística, Heurética ou ars inveniendi era o nome de um certo ramo de estudo, não bem delimitado, pertencente à lógica, à filosofia ou à psicologia, muitas vezes delineado mas raramente apresentado com detalhes, hoje praticamente esquecido. $\mathrm{O}$ objetivo da heurística é o estudo dos métodos e das regras da descoberta e da invenção.
\end{abstract}

Além das aulas com resolução de problemas, houve, também, jogos de raciocínio, como: xadrez, damas, dominó e muitos outros. As aulas com jogos estimularam o pensamento criativo dos educandos jovens. Intercaladas a estas aulas, utilizamos a internet. Todos se conectaram ao site www.somatematica.com, no qual os alunos acessaram os desafios que renderam um bom entusiasmo e satisfação para eles, contribuindo, assim, para o desenvolvimento de um processo criativo em relação à resolução de problemas.

Os resultados descritos na dissertação, são respostas reais da vida real. Percebe-se que houve distração em algumas respostas, houve muita cooperação apesar de terem ocorrido alguns momentos de desânimo para responder. Cada um é atingido de um modo todo particular por uma pergunta, o mais importante é destacar que as situações problemas propostas foram significativas para seus aprendizados e que a perspectiva metodológica da resolução de problemas é eficiente para garantir que os alunos aprendam e consequentemente se desenvolvam, visto que a aprendizagem impulsiona o desenvolvimento.

Destacamos também a criatividade, o raciocínio lógico nas execuções de seus planos e as oportunidades de serem deixados a pensar de "seus jeitos", sem aquela preocupação da formalidade Matemática, para depois, toda vez que terminassem de resolver o problema, as respostas fossem analisadas e devolvidas, contribuindo, desta maneira, para a apresentação das fórmulas e praticidades que a Matemática pode oferecer, sistematizando, seus conhecimentos prévios.

\title{
Conclusão
}

A importância da discussão aqui abordada é atual e pertinente, pois, apesar de haver estudos relacionados à resolução de problemas em desenvolvimento nos últimos trinta anos, a escola ainda trabalha efetivamente muito pouco com a resolução de problemas. 
Predomina a veiculação de exercícios de caráter meramente imitativo-repetitivo, além do fato de poucas pesquisas analisarem a relação professor-aluno e a perspectiva da Educação Matemática numa visão da Teoria Histórico-Cultural enquanto fundamentação teórica da perspectiva metodológica de resolução de problemas. Nesse sentido, considerar o universo sociocultural no qual se ensina nos parece conduta pedagógica que não pode ser adiada já que é a ação que justifica a necessidade da operação Matemática a ser desenvolvida.

Os alunos participantes da pesquisa envolveram-se ativamente de todo o processo e tiveram amplas oportunidades para resolver uma variedade de problemas. Percebo as dificuldades encontradas na resolução das situações-problema, mas o professor leva o aluno a superá-las com diálogo e intencionalidade e visa sempre que o educando aprenda e, consequentemente, se desenvolva.

As variáveis envolvidas na resolução de problemas são muitas, dentre elas, citam-se a afetividade, o contexto, o professor, o aluno, o nível de desenvolvimento de cada aluno, as emoções. Não obstante, se os alunos forem capazes de explicarem como resolveram o problema, os porquês da resolução, o que os levou a desistência ou se copiaram, através desta abertura, serão capazes de apropriarem-se do mecanismo de suas próprias ações.

Com a realização deste estudo chegou-se a conclusão de que a perspectiva metodológica de resolução de problemas proporciona o conhecimento da Matemática, o encaminhamento da formação dos conceitos e o desenvolvimento da criatividade dos educandos.

$\mathrm{O}$ ato de aprender é de grande valia não só para a política educacional, mas sim para toda a sociedade haja vista que a Educação é um dos fatores mais importantes para o desenvolvimento do ser humano, constituindo-se em um pré-requisito essencial para a adequada inserção nas demais instâncias da vida. Também conclui que prevalece, ainda, entre os educandos uma visão infantil e marcada por mitos resistentes a respeito da Matemática. Apesar disso, eles mostraram-se criativos ao resolverem problemas e modificaram sua relação esta disciplina após serem submetidos a aulas na perspectiva metodológica de resolução de problemas.

O professor comprometido com o aluno real (seres humanos que tem na sua frente) e não com o sistema de ensino imposto, quer formar futuros profissionais capazes, competentes, justos, solidários, criativos e amantes do que fazem, pois eles serão nossos futuros médicos, dentistas, advogados, professores, bancários, vendedores, juízes, veterinários, administradores, etc., e ao libertá-los do senso comum e dos paradigmas impostos pela 
sociedade alienadora, libertamo-nos também. Freire já dizia que ninguém liberta ninguém, ninguém se liberta sozinho, mas "os homens libertam-se em comunhão".

Em suma, é primordial que se faça uma ampla revisão na prática pedagógica desenvolvida em Matemática, a fim de que esta contribua positiva e efetivamente para a formação de educandos sujeitos de transformações sociais.

\section{Referências}

BAKTHIN, M. Marxismo e filosofia da linguagem. São Paulo: Hucitec, 1990.

BRUNER, J. S. O Processo da Educação. São Paulo: Nacional, 1968.

DANTE, L. R. Tudo é Matemática. São Paulo: Ática, 2005.

FREIRE, P. Educação como Prática da liberdade. Rio de Janeiro: Paz e Terra, 1969.

Pedagogia do oprimido. Rio de Janeiro: Paz e Terra, 1987.

. Pedagogia da esperança: um reencontro com a pedagogia do oprimido. Rio de Janeiro: Paz e Terra, 1992.

. Pedagogia da Autonomia. São Paulo: Paz e Terra, 1996.

MACHADO, N. J. Matemática e língua materna: Análise de uma impregnação mútua. São Paulo: Cortez, 1999.

MELLO, S. A. Algumas Implicações Pedagógicas da Escola de Vygotsky para a Educação Infantil. Pro-posições, Campinas, 1999.

PIRES, C. M. C. Currículo de Matemática da Organização linear a idéia de rede. São Paulo: FTD, 1999.

POLYA, G. A arte de resolver Problemas. Rio de Janeiro: Interciência, 1978.

POZO, J. I. (Org). A solução de problemas - aprender a resolver, resolver para aprender. Porto Alegre: artmed, 1998.

SCHNEUWLY, B.; DOLZ, J.; Col. . Gêneros orais e escritos na escola. Campinas, SP: Mercado de Letras, 2004.

SMOLE, K. S.; DINIZ, M. I. Ler, Escrever e Resolver Problemas: Habilidades básicas para aprender matemática. Porto Alegre: Artmed, 2001.

VYGOTSKY, L. S. et al. Linguagem, desenvolvimento e aprendizagem. São Paulo: Ícone, 1988. 
VYGOTSKY, L. S. El Problema del entorno. The problem of the environment in the Vygotsky. Readers, 1994. (Tradução- universidade de Havana- Cuba).

. Pensamento e Linguagem. São Paulo: Martins Fontes, 2000. 